\title{
VEGETARIANISMO EN LA GRECIA ANTIGUA
}

Alberto Bernabé ${ }^{1}$

RESUMEN: En Grecia existieron formas de vegetarianismo, pero nunca fueron opciones simplemente dietéticas, sino que obedecían a principios filosóficos o religiosos. Se estudian las propuestas de los órficos, los pitagóricos y Empédocles, señalando las analogías y diferencias entre ellas. Todos comparten la creencia en la transmigración de las almas, pero mientras para los órficos y Empédocles la transmigración es un castigo por un pecado relacionado con el derramamiento de sangre, para los pitagóricos parece ser una mera condición para el mantenimiento de la vida en el universo. Por otra parte, mientras para los pitagóricos y Empédocles el vegetarianismo parece ser consecuente con la idea de que el alma puede transmigrar a animales y, por tanto, postulan una solidaridad entre todos los seres animados, parece que los órficos solo muy tarde postulan la transmigración de almas entre seres humanos y animales, por lo que el motivo fundamental de la abstención de carne es evitar el derramamiento de sangre. Asimismo se examina el uso político que los atenienses hacen del mito de la introducción del cultivo cereal por obra de Deméter.

PALABRAS ClAVE: Vegetarianismo; Filosofía griega; Religión Griega; Orfismo; Pitagorismo.

ABSTRACT: In Greece, there were forms of vegetarianism. Never as a simple dietary option, but obeying philosophical or religious principles. The proposals of the Orphics, the Pythagoreans and Empedocles are studied, pointing out the analogies and differences between them. All share the belief in the transmigration of souls, but while for the Orphics and Empedocles transmigration is the result of a punishment for a sin related to the shedding of blood, for the Pythagoreans it seems to be a mere condition for the maintenance of life in the universe. On the other hand, while for the Pythagoreans and Empedocles vegetarianism seems to be consistent with the idea that the soul can transmigrate to animals and, therefore, postulate a solidarity among all animate beings, it seems that the Orphics only very late postulate the transmigration of souls between humans and animals, so the fundamental reason for abstaining from meat is to avoid the shedding of blood. It also examines the political use that the Athenians make of the myth of the introduction of cereal cultivation by Demeter.

Keywords: Vegetarianism; Greek philosophy; Greek religion; Orphism; Pythagoreanism.

1 Profesor Emérito de la Universidad Complutense de Madrid (Instituto de Ciencias de las Religiones). Este trabajo se incluye en el Proyecto de Investigación financiado por el MINECO FFI2015-65206P.E-mail: albernab@filol.ucm.es. 


\section{Introducción}

"Vegetariano" es un término moderno, surgido a mediados del siglo XIX, con la fundación en Inglaterra de la Vegetarian Society. El propósito de la sociedad era proponer una dieta libre del consumo de carne, en la idea de que era más saludable. Si bien es cierto que hoy día muchos vegetarianos pueden serlo de manera consecuente con un modo de vida que rechace también otro tipo de trato a los animales (su utilización como fuente de bienes de consumo, como las pieles, su maltrato en la cadena de cría y sacrificio o como parte de diversiones que estiman éticamente abominables, como las corridas de toros), el hecho es que muchas otras personas son vegetarianas como una opción dietética, porque estiman que una alimentación a base de vegetales es más saludable, más beneficiosa o sencillamente más apetitosa.

En Grecia existieron formas de vegetarianismo, pero nunca como una opción simplemente dietética. Buena prueba de ello es la diferencia en la terminología usada en la Antigüedad con la del mundo moderno. "Vegetariano" se construye sobre "vegetal", con lo que el término define asépticamente a quien es partidario de su consumo. En Grecia la designación usual para esta opción es “comer alimentos ő́ $u x \alpha ",{ }^{2}$ es decir, “carentes de alma” ( $\left.\psi v \chi \eta ்\right)$, frente a la prohibición de comer alimentos $\check{\varepsilon} \mu \psi v \chi \alpha$, esto es, “dotados de alma”, lo que evidencia que el motivo para la abstención de tales alimentos era la circunstancia de que se consideraban poseedores de alma. 3

Debo comenzar por aclarar que el consumo de carne entre los griegos era habitualmente muy escaso. No debe engañarnos la lectura de los poemas homéricos cuyos protagonistas consumen constantemente vacas a la brasa. Tal práctica formaba parte de una imagen ideal de los héroes del pasado, que se veían como muy lejanos y diferentes de los hombres de la época de los poetas. Lo cierto es que la dieta básica de la Grecia antigua se basaba en cereales y legumbres, mientras que la carne se consumía pocas veces y siempre en conexión con el

\footnotetext{
${ }^{2}$ E. Hipp. 952 (recogido como n. 627 en los fragmentos órficos, ed. Bernabé, a partir de ahora

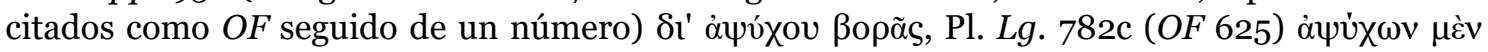

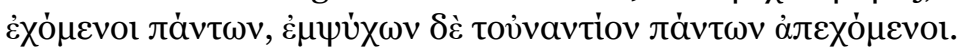

3 Existen algunos testimonios de que la abstinencia de carne podía conectarse a otros principios

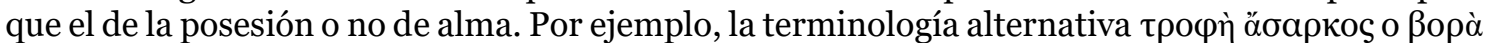
ह̌vбаркоৎ utilizada por Porfirio de Tiro (De Abstinentia 1.1), o la argumentación del propio Porfirio sobre la justicia con los animales en el 1.3 de la misma obra.
} 
sacrificio, esto es, con un momento muy especial de carácter religioso en que la comunidad celebraba un ritual muy preciso que servía, entre otros fines, para reforzar los lazos de cohesión social. La idea de cohesión social es admitida desde cualquiera de las posturas que se han propuesto sobre el sacrificio griego, por diversas que sean (Rudhardt, 1958; Detienne-Vernant, 1979; Burkert, 1983). Así pues, aun cuando no representara una modificación sustancial en la dieta (dada la escasez de carne habitualmente consumida), la negativa a consumir carne obedecía a motivos de carácter filosófico o religioso.

Por otra parte, fueron minoritarios los movimientos de este carácter que propugnaron el vegetarianismo. Prácticamente se reducen a tres: los pitagóricos, los órficos y Empédocles. Hay entre ellos, sin duda, relaciones, pero también notables diferencias, aunque la realidad es que para los propios antiguos esta actitud marginal resultaba muy chocante, lo que provocaba que sus adeptos fueran a menudo confundidos y echados en un mismo saco.

\section{Testimonios sobre la abstención de carne entre los griegos}

\subsection{Confusiones entre órficos y pitagóricos}

Los antiguos (y en ello han arrastrado no pocas veces a los modernos) tendían a confundir órficos con pitagóricos. Muchos autores los citan juntos y ponen de relieve las conexiones entre ellos, sin plantearse poner de relieve los rasgos que los diferenciaban. Unas veces Orfeo es citado primero, lo que tiene su explicación en el hecho de que se le consideraba mayoritariamente un personaje histórico (Bernabé y Casadesús, 2008, p. 13-237) y su participación en la expedición de los Argonautas lo situaba una generación antes de la Guerra de Troya. Otras veces se especifica que los pitagóricos han tomado de él una doctrina, otras se citan órficos y pitagóricos, sin especificar quién ha influido sobre quién. Hay incluso casos en los que obras o doctrinas que mayoritariamente son atribuidas a uno de los grupos aparece en otras fuentes referida al otro. El resultado de todo ello es que no siempre es fácil deslindar los testimonios sobre unos y sobre otros (Bernabé 2013, 2016), pero es posible y necesario procurarlo. 


\subsection{Los órficos y la abstención de carne}

Da la impresión de que el punto de partida de la abstención de carne de los órficos es el deseo de evitar el derramamiento de sangre, una prohibición básica de su modo de vida (De Paz Amérigo y Flores Rivas, en prensa). Así parece indicarlo uno de los testimonios más antiguos sobre la atribución a Orfeo de preceptos de este tipo, un pasaje de Ranas de Aristófanes, en el s. V a. C. (Ar. Ra. 1030-1032 (OF 547 I), seguido por Hor. Poet. 391s. (OF 626)):

Observa en efecto, desde el primer momento cuán útiles resultaron ser los poetas más nobles: Orfeo, en efecto, nos enseñó las teletai y a apartarnos de las matanzas.

No he traducido el término teletai ( $\varepsilon \varepsilon \lambda \varepsilon \tau \alpha i)$ porque la traducción habitual "iniciaciones" no es correcta, dado que no eran solo ritos iniciáticos, sino que se celebraban en otras diversas ocasiones y no hay un término correspondiente en las lenguas modernas que recoja adecuadamente su significado (Sfameni Gasparro, 1988; Jiménez San Cristóbal, 2008; Schuddeboom, 2009). Se trataba de ritos cuya función principal no era rendir culto a las divinidades, sino encontrar en ellos un lenitivo a las ansiedades, angustias y miedos, en especial a la muerte y a la suerte en el Más Allá, de los participantes en ellos. Las más conocidas son las de Eleusis, pero había otras, como las practicadas por los iniciadores órficos. En Eleusis no se preconizaba el vegetarianismo. En cambio los iniciadores órficos asociaban sus teletai a la abstención de derramamiento de sangre y a la alimentación no carnívora, relacionándolas con un mito al que tendré ocasión de referirme más adelante. Centrémonos, pues, en el hecho de que la referencia a "apartarse de matanzas" en un testimonio tan antiguo como Aristófanes alude precisamente a la prohibición de derramar sangre como la principal aportación de la poesía de Orfeo. Naturalmente, si se prohíbe el sacrificio de animales la consecuencia lógica es la prohibición de ingerir carne. Y también tenemos una referencia antigua a esta interdicción en el Hipólito de Eurípides 952-954 (OF 627):

Ahora ufánate y vende que te alimentas de comida sin alma, y teniendo a Orfeo como señor 
entra en éxtasis mientras honras el humo de sus muchos escritos.

Las palabras están puestas en boca de Teseo y se dirigen a su hijo Hipólito. La razón de la violencia verbal del rey ateniense, es que su esposa, Fedra, enamorada de su hijastro y rechazada por él, se había suicidado, dejando un mensaje según el cual se había quitado la vida por la vergüenza que le había provocado las propuestas impropias de Hipólito. Teseo cree entonces que su hijo, quien aparentemente no había mostrado nunca interés por el sexo, es un tartufo, un hipócrita, y lo equipara a los órficos, que probablemente se abstenían del sexo, y al parecer generaban desconfianza sobre la sinceridad de sus intenciones en la Atenas de la época. Es por ello por lo que le atribuye a Hipólito la alimentación propia de los seguidores de Orfeo, usando el término “técnico” ő $\psi u x \alpha$, “comida sin alma”.

En otro pasaje, un fragmento de Cretenses fr. 472 Kannicht ( $O F$ 567), 4 un coro de santos varones cretenses hace su presentación en la párodo y hace referencia a rasgos propios de los órficos (Casadio, 1990, y para este pasaje en contraposición al anterior, Bernabé, 2016a), entre ellos, la consabida referencia a la abstención de comer seres dotados de alma:

Con vestidos totalmente albos rehúyo

la generación de los mortales y los sarcófagos, sin acercarme a ellos, y me guardo de nutrirme de alimentos en los que hay alma.

Por indicar un último testimonio antiguo muy valioso, Platón, Leyes $782 \mathrm{c}$ (OF 625) hace referencia a lo que denomina "las vidas llamadas órficas":

Hemos oído decir que en otros [pueblos] ni se atrevían a probar la carne de vaca; las ofrendas a los dioses no eran animales, sino tortas y frutos bañados en miel y otras víctimas puras similares a estas y que se abstenían de la carne porque no era santo comerla ni contaminar con sangre los altares de los dioses. Nuestra vida entonces era como una de las llamadas órficas, limitadas a todo lo inanimado y por el contrario, apartadas de todo lo que tenga alma.

\footnotetext{
4 Es significativo que el pasaje es citado precisamente por Porfirio (De abst. 4.19).
} 
Platón coincide con los otros textos presentados en poner de manifiesto la relación del mensaje de Orfeo con la abstención de carne y la de esta con el derramamiento de sangre. Una y otra vez, lo determinante para decidir si la comida era o no lícita era la posesión de “alma”, es decir, el hecho de tratarse de un ser vivo.

\subsection{Los pitagóricos y la abstención de carne}

Otras fuentes usan los mismos términos técnicos, alimentos dotados de alma ( $\alpha ُ \psi \cup \chi \alpha)$ y no dotados de alma ( $\left.\varepsilon_{\mu} \mu \cup \chi \chi \alpha\right)$ para referirse al régimen alimenticio de los pitagóricos. Los cómicos atenienses del s. IV a. C. se refieren varias veces a tal interdicción alimenticia por parte de los seguidores de esta escuela filosófica, que deberían de resultar muy extravagantes a ojos del ateniense común (Bernabé, 2014).

En efecto, en un fragmento de la comedia titulada precisamente $E l$ Pitagórico, el cómico Aristofonte (fr. 12 Kassel-Austin (OF 431 III)) presenta un personaje, que le refiere a otro lo que un tercero, quien al parecer había bajado a los infiernos, había contado sobre la vida allí:

Dijo que, una vez que bajó a donde vivían los de abajo vio a unos y a otros, y que se diferencian del todo los pitagóricos de los demás muertos. Pues solo a ellos les dijo Plutón que le acompañaran en el banquete por su piedad.

$[\ldots]$

y comen

verduras y beben sobre todo agua.

Observamos que al vegetarianismo se añade ahora un segundo precepto alimentario, la abstención de vino. En ambos aspectos insiste otro cómico, Alexis, en una comedia titulada Los Tarentinos (fr. 223.1-3 Kassel-Austin):

Pues los que pitagorizan, según hemos oído, no comen ninguna comida en absoluto dotada de alma. Y son los únicos que no beben vino. 
Sin embargo, en la continuación del pasaje (fr. 223.4-6 Kassel-Austin), hace un divertido juego de palabras entre los significados de $\dot{\mu} \mu \psi u x \circ v$ "dotado de alma" y "vivo":

B. Pues Epicárides bien que comía carne de perro, pese a ser un pitagórico. A. Pero después de matarlo, así que ya no está dotado de alma.

En otras fuentes parece haber contradicciones sobre la dieta pitagórica, que pueden deberse a que hubo pitagóricos en muchas épocas y en muchos lugares y a que quizá no siempre mantuvieran los mismos preceptos. Sin embargo la dieta vegetariana aparece una y otra vez como un rasgo definitorio de los seguidores de este movimiento filosófico. Así Calímaco (fr. 191.62 Pfeiffer), ya en el siglo III a.C., atribuye al Samio la enseñanza de no comer "seres que respiran"

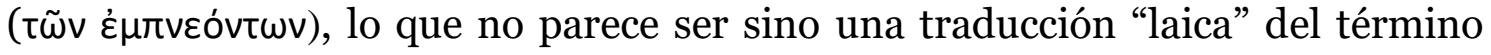
habitual "dotados de alma". Siglos más tarde, a caballo entre el II y el III d.C., Filóstrato, Vida de Apolonio de Tiana (6.11), se refiere al seguidor de Pitágoras del s. I d.C. al que dedica su biografía, señalando que seguía el modo de vida de Pitágoras que, entre otros rasgos, comportaba que "mantenía su vientre sin

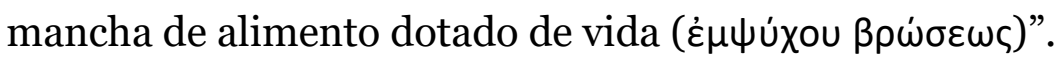

\subsection{Empédocles y la abstención de carne}

El hecho de que la terminología del vegetarianismo en Grecia se derive del término $\psi$ uxń parece indicar que en la base de la prohibición de derramar sangre y comer carne se encontrara una doctrina referida al alma, pero tal relación no se especifica en los pasajes que he recogido hasta ahora. Sin embargo otro autor que comparte la misma prohibición alimentaria, Empédocles, ofrece una explicación de sus motivos. 5 El filósofo de Acragante, del s. V a.C., expone una teoría de la transmigración, según la cual un demon castigado (podríamos decir, sin entrar en disquisiciones muy profundas, que demon equivale, aunque

\footnotetext{
5 Cf. Balaudé (1997), que considera al acragantino iniciador de una teoría de la "parenté du vivant", esto es, de la solidaridad entre los seres vivos, que influiría notablemente sobre doctrinas posteriores.
} 
no sea lo mismo, a un alma) va pasando de un cuerpo a otro (fr. 107.7-8 Wright = B 115.7-8 Diels y Kranz):

En la hechura de formas mortales, variadas en el tiempo, mientras que va alternando los procelosos rumbos de la vida.

Aún más claramente lo afirma en el otro fragmento (108 Wright = B 117 Diels y Kranz):

Que yo he sido antes un joven y una joven, un matorral y un pájaro, y un mudo pez del mar.

Lo que quiere decir que su daimon había ido habitando en diversos seres, antes de hacerlo en su propio cuerpo. Sin embargo, es el siguiente texto en el que se relacionan inequívocamente entre sí transmigracion y prohibición del sacrificio, dado que se afirma que un antepasado puede volver a encarnar en otro ser. Empédocles imagina truculentamente la escena en que familiares sacrifican una res que resulta ser depositaria del alma de un familiar (fr. 124.1 Wright = B 137.1 Diels y Kranz):

Alza el padre un hijo suyo transmutado en su figura para degollarlo entre plegarias, el gran infeliz. Y los otros, presa del error, van a sacrificarlo, mientras los implora. Pero aquel, sordo a los quejidos, después de degollarlo, en las estancias dispone el sórdido festín.

De igual modo un hijo que toma a su padre, o a su madre unos niños, les arrancan la vida y la carne antes amada la devoran.

\subsection{Conclusiones sobre la abstención de carne}

A la vista de los textos, parece que podemos atribuir a órficos, pitagóricos y Empédocles, una doctrina en la que se prohíbe el consumo de carne. Algunos autores no tienen claro dónde se origina el principio e incluso confunden a menudo a órficos y pitagóricos. Es interesante señalar, ahora, si las motivaciones de estas ideas son o no comunes. Para ello, acudiremos de nuevo a los textos. 
3 En busca de los fundamentos ideológicos y religiosos del vegetarianismo

\subsection{Razones del vegetarianismo en los órficos}

La prohibición órfica del consumo de carne se fundamentaba en un mito que daba cuenta del origen de los seres humanos. Tal tema resulta poco frecuente en el ámbito griego, donde apenas encontramos otros mitos que se refieran a él (Bernabé y Pérez de Tudela, 2011). Por ejemplo, en el único poema cosmogónico griego que se ha conservado completo, la Teogonía de Hesíodo, se menciona el origen de la primera mujer, Pandora, pero no hay ninguna referencia a cómo surgieron los hombres en el mundo.

La existencia en la Antigüedad de un mito órfico que fundamentaba las creencias del grupo se ha puesto en duda por algún autor (sobre todo por Edmonds, 1999), pero con argumentos poco convincentes. Como resultado del cotejo de diversas fuentes antiguas (Bernabé, 2002, 2008), puede obtenerse un relato bastante coherente, que es el siguiente:

El primer rey de los dioses, Urano (es decir, el Cielo), mantenía constantes relaciones sexuales con su esposa Gea (la Tierra) para no dejar nacer a sus hijos, con objeto de que estos no le arrebataran el poder. Pero la Tierra pide a Crono, uno de sus hijos, que castre a Urano, de forma que las relaciones sexuales se interrumpen drásticamente y por fin ella puede dar a luz a sus hijos. Crono ocupa entonces el trono divino y, con el mismo propósito de no perder el poder, engullía a sus descendientes a medida que iban naciendo, con objeto de que se quedaran, nonatos para siempre en su vientre masculino y, por tanto, incapacitado para parir. Pero su esposa, Rea, cuando nació Zeus, le dio a su esposo, en vez del niño, una roca envuelta en pañales para que la engullese, tras lo cual ocultó a Zeus en una cueva y consiguió así salvarlo. Cuando Zeus creció, hizo que Crono vomitara a sus hermanos y tomó el poder sobre los dioses. Hasta aquí, el mito órfico es coincidente casi por completo con el que cuenta Hesíodo en su Teogonía, pero esta lo termina en este punto, mientras que en el mito órfico la historia continuaba en la siguiente generación. Zeus comete entonces incesto con su madre, Rea, identificada con Deméter, y tiene como hija a Perséfone, tras lo cual se unió con su hija y como resultado de dicha unión nació el dios Dioniso, fruto, por tanto, de un doble incesto y que resulta ser a la vez hijo, nieto y 
hermanastro de Zeus. El motivo de esta distorsión de las generaciones era evitar el orden sucesorio normal (ya no había un "descendiente" que lo destronara) y convertir a Dioniso en una especie de alter ego de sí mismo. Por ello debemos interpretar que, cuando Zeus decide transmitirle el cetro a Dioniso cuando aún era solo un niño, ello no era considerado por él un destronamiento, sino que de alguna manera continuaba manteniéndose en el poder a través de su hijo.

Sin embargo, Hera, la esposa de Zeus y madrastra del recién nacido (y que, por lo tanto, no veía en absoluto con buenos ojos el plan), trata de destruir a Dioniso. Para ello aprovecha que los Titanes, dioses de la segunda generación y por tanto destronados, veían con enorme envidia la dignidad regia que se le había otorgado al niño, para instigarlos contra él. Los Titanes se disfrazan embadurnando sus caras con yeso y engañan a Dioniso con diversos juguetes para matarlo. Cometido el crimen, lo despedazan, lo cocinan y lo devoran, dejando solo su corazón. El sacrificio de Dioniso se convierte así en manos de los órficos en el abominable paradigma del sacrificio cruento, que queda convertido para ellos en una práctica nefanda.

Lleno de ira por el crimen de los Titanes, Zeus, los fulmina con el rayo, pero de consigue resucitar un nuevo Dioniso a partir de su corazón. Pero de los restos de los Titanes caídos sobre la tierra, de la mezcla que se produce entre el fuego del rayo, las cenizas y la sangre de los Titanes con la tierra, surgen los seres humanos.

Tal origen violento de la humanidad tiene diversas consecuencias. En primer lugar, dado que los seres humanos en parte proceden de dioses (los Titanes y Dioniso) y en parte de la tierra, tienen una parte inmortal y divina, el alma, y una parte mortal y corruptible, el cuerpo. Pero también el alma tiene dos componentes divinos, uno positivo, que procede de Dioniso, y otro negativo, resto de la "naturaleza titánica", esto es de la soberbia de sus antecesores, los Titanes.

Como resultado de todo ello, el alma de los hombres, antes del propio origen de la especie, fue contaminada por un crimen, el de los Titanes, que debía ser expiado. Tal expiación consistía en la necesidad de que el alma fuera castigada durante un largo espacio de tiempo, consecuente con la magnitud del crimen cometido, y por lo tanto superior a la duración de una sola vida. Como consecuencia, el ingreso del alma en un cuerpo, que es para ella como un sepulcro, la necesidad de purificarse y expiar el delito y la liberación a la muerte del cuerpo, 
se repite varias veces, en un proceso muy largo. A él alude Platón en un famoso pasaje del Crátilo (400c, OF 430 I; cf. Bernabé, 2011, p. 115-143):

En efecto algunos afirman que este [el cuerpo] es sepultura del alma, como si esta estuviera sepultada en su situación actual [...] me parece que Orfeo y los suyos le pusieron este nombre sobre todo porque el alma, que paga el castigo por lo que debe pagarlo, lo tiene como un recinto, a semejanza de una prisión [...] hasta que expíe lo que debe.

Llamamos metempsicosis (Casadio 1991; Bernabé, Kahle y Santamaría, 2011) a la transmigración del alma desde el otro mundo a este y de un cuerpo a otro, hasta que, expiadas sus culpas, pueda lograr su liberación. Para lograr la liberación del alma y para que, definitivamente separada de cualquier cuerpo, pueda llevar una vida dichosa en el otro mundo, el hombre debe, primero, iniciarse en los misterios dionisíacos en los que se usaban los poemas de Orfeo, luego, mantener una vida de estricta pureza, no contaminada con sangre ni con ningún ser muerto, para no agravar su situación, y celebrar diversos ritos específicos, el más importante de los cuales era la telete.

Diversos autores (como Casadio, 1991, p. 127; incluso yo mismo (Bernabé, 2011, p. 193) explicaron el vegetarianismo órfico como una respuesta a la idea de que la reencarnación podía producirse en animales, de modo que consumir carne era un acto de canibalismo practicado con un congénere. $Y$ en efecto, hay un pasaje en las Rapsodias ( $O F$ 338, un poema órfico que se data entre los siglos II-I a.C.) en que ello parece afirmarse:

Los mismos son padres e hijos en las casas, decorosas esposas, madres e hijas;

nacen unos de otros con la mudanza de las generaciones.

$[\ldots]$

Pues el alma, mudada según los ciclos del tiempo

transmigra de hombres a unos y otros animales:

unas veces viene a ser caballo, otras ...6

otras veces oveja, otras, ave de pavoroso aspecto, otras en cambio cuerpo canino y voz profunda, y estirpe de gélidas sierpes que se arrastra en la divina tierra.

\footnotetext{
${ }^{6}$ Hay una laguna en el texto.
} 
Sin embargo, De Paz Amérigo y Flores Rivas (en prensa) han puesto de manifiesto que los testimonios de reencarnación en animales para el orfismo son tardíos y más bien escasos; de hecho, el único claro es el que acabo de citar. Por ello, su carácter aislado lleva a los autores a considerar que las ideas que contiene este fragmento han sido probablemente reelaboradas a partir de influencias platónicas o pitagóricas.

Además los autores examinan otro fragmento ( $O F$ 339) que parece un tanto contradictorio con el anterior y que probablemente se remonta a una fecha más antigua:

Cuando de las fieras y los pájaros alados

se precipitan las almas y les falta la sagrada vida,

al alma de estos nadie la conduce a la mansión de Hades, sino que volando queda en vano por ahí, hasta que de ella, mezclada con los embates del viento, se apodera otro ser. Mas cuando un hombre abandona el resplandor del sol, sus almas inmortales abajo se las lleva Hermes Cilenio, a la descomunal cavidad de la tierra.

Aquí está claro que el poeta diferencia netamente los procesos de hombres y animales a la hora de reencarnarse (Casadio, 1991, p. 138; Bernabé 2011, p. 195). Incluso las almas de los seres humanos son las únicas en ser

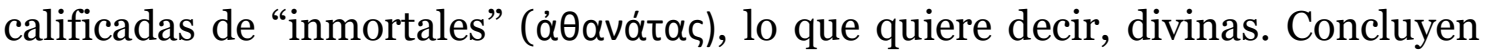
con razón De Paz Amérigo y Flores (en prensa) que el poeta plantea dos tipos de reencarnación independientes para dos tipos de alma diferentes: las almas de los animales, que reencarnan en animales, y las almas humanas, que reencarnan en seres humanos.

Por otra parte, si el ser humano pudiera reencarnar en un animal, perdería la posibilidad de iniciarse en los misterios y de salvar su alma, lo cual sería contradictorio con una posición tan ritualista como la órfica, en la que es precisamente la participación en los ritos el instrumento fundamental para la salvación y el final del ciclo de renacimientos. Un alma reencarnada en animal dejaría a este en indefensión para salvarla, al no poder participar en las teletai. Nos queda, pues, como explicación del vegetarianismo órfico el rasgo que en todos los textos se pone de manifiesto: no es tanto que se condene el consumo de 
carne cuanto la condición sine qua non para dicho consumo: el derramamiento de sangre del animal sacrificado. Es la necesidad de pureza, incompatible con la efusión de sangre la que lleva al órfico a evitar la relación con la alimentación animal.

\subsection{Fundamentos del vegetarianismo en Empédocles}

Empédocles configura un sistema filosófico complejo, compuesto por una faceta más "fisica" y otra más religiosa. La faceta "física" postula la existencia de cuatro "raíces": aire, agua, fuego y tierra, que pasan por ciclos de combinación, unidos por la acción de un principio llamado Amor, y de disgregación, separados por la acción de un principio contrario, Odio. Según la faceta más religiosa, el filósofo se presenta a sí mismo como un daimon que cometió una grave culpa y tiene por ello que sufrir el castigo de encarnarse y vivir en la tierra. La culpa consistió precisamente en el consumo de carne, que estaba prohibido por un antiguo juramento de los dioses (Empédocles B 115 y 139 Diels y Kranz + Papiro de Estrasburgo d 6):

Hay un decreto de Necesidad, de antiguo refrendado por los dioses, eterno, sellado por prolijos juramentos:

"Cuando alguno, por errores de su mente, contamina sus miembros $\mathrm{y}$ viola por tal yerro el juramento que prestara - hablo de démones a los que toca una vida perdurable -, ha de vagar por tiempos tres veces incontables, lejos de los Felices, en la hechura de formas de mortales, variadas en el tiempo, mientras que va alternando los procelosos rumbos de la vida, pues la fuerza del éter lo impulsa hacia la mar y la mar lo escupe al terreno de la tierra, y a su vez esta a los fulgores del sol resplandeciente, mas él lo precipita a los vórtices del éter; cada uno de otro lo recibe, mas todos lo aborrecen". Yo soy uno de ellos, desterrado de los dioses, errabundo, y es que en la Discordia enloquecida puse mi confianza.

\section{[...]}

iAy de mí, que no acabó conmigo un día implacable, antes de haber concebido con mis garras terribles acciones para comer. 
Frente a la explicación órfica, en la propuesta de Empédocles han desaparecido los Titanes como causantes del castigo, ya que el responsable es el propio daimon que, movido por Discordia, rompe el juramento que prohíbe comer carne. Sigue existiendo la idea de una culpa originaria, y el hecho de que consista precisamente en el consumo de carne. Asimismo vimos que se relaciona expresamente la prohibición de este consumo con el hecho de que un alma puede reencarnar en un animal. Es la devoración de carne la que produce la ruptura de esta harmonía, por haberse violado la ley universal de no matar animal alguno. Por ello el filósofo exhorta a sus conciudadanos a no continuar con esa práctica, causa de todos sus problemas (Empédocles B 136 DK):

¿No pondréis fin a esta matanza disonante? ¿No estáis viendo que os devoráis unos a otros por la incuria de vuestra inteligencia?

\subsection{Fundamentos del vegetarianismo en los pitagóricos}

Al tratar de determinar los fundamentos ideológicos del vegetarianismo en los pitagóricos, nos encontramos con que ninguna fuente antigua se refiere a la cuestión, de modo que debemos tratar de buscarlos en la coherencia de sus ideas filosóficas. Sabemos que los pitagóricos postularon que el alma era inmortal y que a la muerte del cuerpo que la alojaba, pasaba a otro. Pero no tenemos ningún motivo para suponer que los pitagóricos creyeran que ello sucedía porque se había cometido un pecado, ni tampoco hay ninguna referencia a que cada alma se liberaría algún día y dejaría de reencarnar. Todo parece indicar que los pitagóricos consideraban que las almas reencarnaban porque ese es el orden normal de las cosas, el que asegura la continuidad de la vida.

De Paz Amérigo y Flores Rivas (en prensa) señalan que la transmigración de las almas en el pitagorismo forma parte de un intento de explicación totalizadora y reduccionista de la realidad que, a través de una ley general, trata de dotar al universo de unidad y homogeneidad. Las almas podían pues ocupar el cuerpo de cualquier ser animado, lo que quiere decir que se atribuye a unos y otros el mismo tipo de alma (Riedweg, 2008, p. 63; Zatta, 2017, p. 100). Ese fundamento ideológico es el que incita a respetar a los animales, que todos los seres vivos pueden ser portadores de un alma de igual naturaleza que la que 
anima a los seres humanos y en consecuencia, se encuentran en un mismo nivel de respeto, en tanto que el más humilde de los animales puede ahora albergar el alma de alguno de nuestros antepasados o podrá albergar la nuestra en el futuro.

\subsection{La dieta cereal y la política}

Una extraña derivación del vegetarianismo antiguo es la existencia de particulares relaciones con la política. Tales relaciones se han señalado en diversos frentes. Por una parte, Detienne (1975) postula que la consideración del sacrificio cruento como un crimen comportaba el rechazo de un rito central en la religión del Estado para generar vínculos en la comunidad, lo que debió de provocar problemas de alejamiento de la sociedad de quienes propugnaban tales ideas. Es sin duda una posibilidad, tan lógica como atractiva, pero no es menos cierto que no tenemos constancia de que tales conflictos se hayan producido (Herrero, 2008).

Una segunda manifestación de la relación de vegetarianismo y política se encuentra en la reivindicación del establishment ateniense, que no propugnaba el vegetarianismo, pero que sí utilizó un mito eleusinio en el que se conmemoraba la adopción de la dieta cereal, como un elemento de la propaganda ática y una defensa de su imperialismo a través de la presentación del mito como un elemento civilizador esencial.

En efecto, el mito ateniense que servía de fundamento a los misterios eleusinios contaba que, cuando Hades raptó a Perséfone, su madre, Deméter, la buscó en vano, hasta que unos campesinos de Eleusis le informaron de dónde estaba, de modo que la diosa, como muestra de gratitud, le concedió a Triptólemo, un príncipe eleusinio, el beneficio de la agricultura, que hasta entonces era una práctica desconocida. Muchos vasos áticos de figuras negras desde el s. VI a.C. (Schwarz 1987; 1997) representan a Triptólemo en un carro volador desde el que el héroe regala a la humanidad las espigas para difundir entre ellos el cultivo del cereal, como una nueva forma de alimentarse (sobre la utilización política del mito, Matheson, 1994).

Conocemos que hubo un poema ático de propaganda eleusinia, que debió 
de componerse entre los siglos VI y V a. C.7 (Blomqvist, 1990) y que se le atribuyó al prestigioso Orfeo, el fundador de todas las teletai, según la tradición (Bernabé, 2008a). El comienzo es citado por Sexto Empírico, Contra los Profesores (2.31, OF 641):

Hubo un tiempo en que los hombres tenían una vida de mutuo canibalismo y el más fuerte mataba al varón más débil.<smiles>[CH]1[CH]CC1</smiles>

Y los peces, las fieras y los pájaros alados

se comían unos a otros, porque no había justicia entre ellos.

Introduce esta cita una presentación en prosa (OF 641) en la que se aclara que la divinidad se compadeció de las miserias de los seres humanos y envió al Ática a las diosas legisladoras (Deméter y Perséfone), para que pusieran fin a la mutua devoración y crearan una vida civilizada, basada en el consumo de cereales y en la represión de la injusticia. Es más que probable pensar que Aristófanes tenía en mente este poema cuando le atribuye a Orfeo haber puesto fin a las matanzas con las enseñanzas de sus poemas (Ranas 1030-1032 = OF 547, citado en $\S 2.2)$.

Otro fragmento literal del mismo poema presenta a los dioses vigilando las acciones humanas ( $O F$ 643):

Vestidos de niebla van y vienen por la tierra toda,

vigilando las acciones soberbias y las buenas normas de los hombres.

Parece, pues, que el poema no se limitaba a la referencia del descubrimiento del cereal, sino que también se refería a una vigilancia ejercida por los dioses sobre el comportamiento moral de los seres humanos. La práctica de la agricultura se asocia de este modo a la instauración de la ley y el orden, político y moral, como si la transformación de la humanidad de salvaje en civilizada estuviera íntimamente asociada a los orígenes de la agricultura y de la dieta cereal. Los atenienses asumen en cierta medida el papel de los dioses como vigilantes del orden moral.

7 El motivo de tal datación es que parece haber sido aludido o parodiado por Critias (s. V a.C.) $T G r F 43$ F 19, y por Mosquión (s. III a.C.) $T G r F 97$ F 6. 
En efecto, la propaganda ática hizo uso abundante de esta tradición que relaciona los misterios con el origen de la agricultura y la civilización, con objeto, entre otros, de reclamar de sus aliados primicias en pago por este gran servicio que habían prestado a la humanidad. Así lo testimonian un par de inscripciones áticas antiguas, Inscriptiones Graecae I3 78 (ca. 422?), II² 140 (IV a.C.), en las que se consignan tributos por ese motivo, así como algunos textos literarios, como Isócrates (Panegírico 31, 38) o Jenofonte (Helénicas 6.3.6), que insisten en el derecho que asiste a los atenienses para recabar tributos, dada su condición de benefactores de la humanidad (Cavanaugh, 1996; Burkert, 2007, p. 94-95).

El ejemplo más significativo de esta actitud de los autores áticos es un orador, profundamente implicado en los valores de la educación ciudadana y en la defensa de la ética, Isócrates. En diversos textos en los que trata de los Misterios Eleusinios, Isócrates no solo se refiere a los beneficios procurados por la agricultura, presentada como símbolo de la vida civilizada, sino incluso a la promesa de una vida feliz en este mundo y en el otro que puede cumplirse com resultado de la iniciación. En el primero de ellos (Isócrates, Panegírico 28) señala:

Deméter, cuando estaba errante tras el rapto de Core, fue benévolamente tratada por nuestros antepasados, ${ }^{8}$ con unos servicios que no pueden entender sino los iniciados, y les dio dos tipos de recompensas: las más importantes fueron las cosechas, causa de que no vivamos como fieras, y la celebración de los misterios, que dan a los iniciados las más dulces esperanzas para el final de la vida y para toda la eternidad.

Isócrates asegura que los atenienses fueron los primeros que dejaron de vivir como fieras, para hacerlo como verdaderos seres humanos, en la medida en que ya no se alimentaban solo de la carne de otro animal, sino que cultivaban el cereal y basaban su dieta en él. Y digo "no se alimentaban solo" porque, aunque el discurso no lo dice, sabemos que la práctica de la agricultura y el consumo de cereal no representó en absoluto que los atenienses dejaran de comer carne, cosa que seguían haciendo en los sacrificios. Con todo, merece la pena ver en la continuación del discurso a dónde nos lleva Isócrates (Panegírico 29-31):

\footnotetext{
${ }^{8}$ Los atenienses. Se refiere al mito narrado supra.
} 
Nuestra ciudad se comportó de un modo tan reverente con los dioses y tan filantrópico, que cuando fue señora de bienes tan fundamentales no los sustrajo a los demás, sino que hizo partícipes a todos de tal legado. Y aún hoy enseñamos cada año colectivamente los usos, los cultivos y las ventajas que se derivan de las cosechas.

Isócrates se vanagloria de que Atenas podría haber disfrutado sola de la gran revolución alimentaria asociada al origen de la vida civilizada, pero, en su inmensa generosidad, decidió hacer a las demás ciudades partícipes de ella. El orador habla de ello a propósito de los misterios, probablemente porque esta enseñanza se recibía cuando se participaba en los Misterios de Eleusis. Prosigue Isócrates (Panegírico 31):

Pues la mayoría de las ciudades, en conmemoración del antiguo favor, nos envía cada año las primicias del cereal; y a algunas que dejaron de hacerlo, la Pitia les ordenó entregar su parte de las cosechas y cumplir así las tradiciones con nuestra ciudad.

Con esta sutil alusión a una institución tan sumamente respetada en toda Grecia como la Pitia délfica - quien, en respuesta a la pregunta de si se debía pagar el tributo a los atenienses, había contestado que por supuesto que sí -, Isócrates convierte el mito de la fundación de la civilización en argumento político para justificar el imperialismo ateniense. ¿Cómo las ciudades vasallas pueden negarse a pagar tributo a Atenas si le deben a esta ciudad el benéfico tránsito de la vida salvaje a la civilizada? ¿Y cómo hacerlo, además, si la práctica había sido refrendada por Delfos?

Isócrates concluye, poco más adelante (Panegírico 38), lo que se deducía de todo lo dicho antes: la civilización no existiría sin los atenienses

(Atenas) se preocupó tanto de lo demás que ninguno de los bienes de los que los hombres disfrutan ahora, no por haberlos obtenido de los dioses, sino alcanzados por nosotros mismos, existiría sin ayuda de nuestra ciudad.

Los atenienses se presentan así como la comunidad civilizadora, generosa, que había traído la felicidad y la concordia a los pueblos y por ello tenía derecho a reclamar de ellos no solo agradecimiento eterno, sino, en un nivel más material, un tributo que les era debido, como si fueran los royalties de la patente 
que les pertenecía. A través del mito y del ritual eleusinio, con el apoyo de la formidable propaganda que eran los vasos áticos pintados, que difundían el Athenian way of life por todo el Mediterráneo, se presentaba como la cuna de la civilización, la quintaesencia de la vida civilizada, la ciudad que, al comunicar generosamente a las demás el cultivo cereal y todo lo que este representaba, las había sacado de la barbarie, representada por la dieta carnívora, asociada al derramamiento de sangre, la injusticia, y el abuso, y las había convertido en comunidades presididas por la ley, el respeto y la justicia. Todo lo cual, insisto, en absoluto representaba la prohibición, ni siquiera, la recomendación de utilizar exclusivamente la dieta cereal y evitar el consumo de carne.

Con todo, el mito eleusinio de Triptólemo tiene sus ecos en algunos filósofos. Jenócrates en Porfirio, De Abstinentia 4.22 (fr. 252 Isnardi-Parente) atribuye a Triptólemo tres leyes: honrar a los padres, ofrecer a los dioses

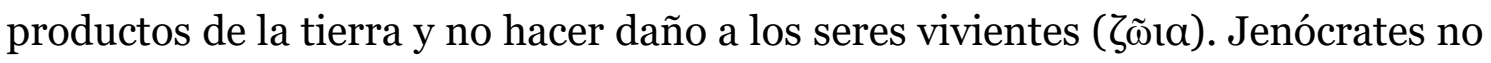
tiene duda sobre las dos primeras, pero se plantea cuál es el sentido último de la tercera y, a su vez, Porfirio, muestra sus reservas sobre algunos argumentos de Jenócrates.

\section{Falta de continuación del vegetarianismo}

Los usos políticos de la atribución a los atenienses de la difusión de la dieta cereal terminaron al tiempo que el propio Imperio Ateniense, y las prácticas de órficos y pitagóricos llegaron con el tiempo a convertirse más bien en una rareza, de forma que podemos concluir que el vegetarianismo nunca llegó a ser un movimiento popular en Grecia. Si bien es cierto que hay testimonios aislados de la defensa del sacrificio no cruento, como un texto de Teofrasto citado por Porfirio, De abstinentia 4.22 (584A Fortenbaugh) y otros pasajes, recogidos sobre todo en el tratado de Porfirio, que indican que algunos filósofos mostraron interés por la cuestión - no podemos entrar en el detalle -, el hecho es que los sacrificios cruentos siguieron celebrándose hasta el triunfo del cristianismo (que tampoco fue nunca vegetariano). Y aunque Plutarco, el gran erudito que recoge y concentra una larga tradición de la cultura griega, trata de la cuestión, incluso de forma monográfica en el De esu carnium (cf. Newmyer 2013), también asevera en el Banquete de los Siete Sabios (159C; cf. Pinnoy, 1990, p. 204; Bernabé 1996, 
p. 65, 83, 92): "Abstenerse del consumo de carne, como cuentan que hacía el antiguo Orfeo, es más un sofisma que una manera de huir de las injusticias que comporta la nutrición".

\section{Colofón}

Creo que ha podido quedar claro, a partir de lo que hemos examinado, que en Grecia se iniciaron algunos movimientos que defendieron el consumo de alimentación vegetal, a expensas de la dieta carnívora. Sus propuestas tienen su fundamento en principios de carácter religioso y filosófico - en época antigua religión y filosofía no tienen unos márgenes tan nítidos como podríamos pensar.

Al parecer los órficos propugnaron el vegetarianismo de forma absoluta, si bien el centro de su negativa no se situaba en la carne en sí como alimento ni se asociaba a la idea de la transmigración de las almas - ya que todo parece indicar que no creían que las almas podían transmigrar de los seres humanos a animales -, sino en el derramamiento de sangre, condición sine qua non para que los seres "con alma" pudieran ser consumidos.

Los pitagóricos, al menos su corriente mayoritaria, adoptan el vegetarianismo porque consideran que existe una especie de solidaridad de los seres de la naturaleza, y porque la reencarnación en la que creían (que ni es secuela de un castigo ni prevé su finalización a través de rituales) excluye la idea de derramar sangre de un congénere, de modo que consumir carne sería una especie de canibalismo. No cabe duda de que entre órficos y pitagóricos pudo haber (y de hecho, parece que hubo) interferencias.

Empédocles, por su parte considera que las reencarnaciones obedecen a una ley universal que castiga largamente a quienes consumen carne y, además, extiende la posibilidad de que el alma se aloje en vegetales.

En la propaganda ática de los Misterios Eleusinios no hay interdicción del consumo de carne, aunque sí una defensa de la dieta cereal, asociada a la civilización, al progreso y a la racionalización de la vida humana, si bien lastrada por una utilización ideológica al servicio de intereses económicos.

Por otra parte, mientras que en Empédocles y los Pitagóricos el vegetarianismo se asocia a la idea de la transmigración, los órficos parecen estar menos comprometidos con esa idea. Por otra parte, los órficos y Empédocles 
interpretan la transmigración como un castigo, debido a un pecado originario, relacionado con el derramamiento de sangre y el consumo de carne, mientras que los pitagóricos parecen entender la transmigración en el orden normal de las cosas, la garantía de la conservación de la vida en la naturaleza, por lo que consideran que el vegetarianismo es la respuesta a una creencia en la solidaridad fundamental de los seres vivos.

Con el tiempo, el vegetarianismo va siendo cada vez menos popular, es criticado por autores como Plutarco y los cristianos no lo introducen en su sistema de creencias - es más, diríamos entre paréntesis, que el hecho de proponer que el pan y el vino consagrados son el cuerpo y la sangre de Cristo hicieron creer a sus detractores que los cristianos practicaban el canibalismo en sus ritos. El triunfo del cristianismo y el rechazo de este del vegetarianismo representó el abandono durante siglos de propuestas vegetarianas.

Artículo recibido el 08.01.2019, aprobado el 20.02.2019.

\section{BIBLIOGRAFÍA}

Balaudé, Jean-François. Parenté du vivant et végétarisme radical: Le "défi" d'Empédocle. In: Cassin, Barbara; Labarrière, Jean-Louis et Romeyer-Dherbey, Gilbert (eds) L'Animal dans l'Antiquité. Paris: Vrin, 1997, p. 31-53.

Bernabé, Alberto. Plutarco e l'orfismo. In: Gallo, Italo (ed.) Plutarco e la Religione, Atti del VI Convegno Plutarcheo (Ravello, 29-31 maggio 1995). Napoli: M. D’Auria, 1996, p. 63-104.

. La toile de Pénélope: A-t-il existé un mythe orphique sur Dionysos et les Titans? Revue de l'Histoire des Religions, 219, 2002, p. 401-433.

El mito órfico de Dioniso y los Titanes. In: Bernabé, Alberto y Casadesús, Francesc (eds) Orfeo y la Tradición Órfica. Un Reencuentro. Madrid: Akal, 2008, p. 591-608.

. Orfeo y Eleusis. Synthesis 15, 2008a, p. 13-36 (versión en inglés: Orpheus and Eleusis. Thracia, 18, 2009, p. 89-98).

. Platón y el Orfismo. Diálogos Entre Religión y Filosofía. Madrid: Abada, 2011 (Trad. portuguesa Platão e o Orfismo, Diálogos Entre Religião e Filosofia. São Paulo: Anablume, 2011).

Orphics and Pythagoreans: The Greek perspective. In Cornelli, Gabriele; McKirahan, Richard; Macris, Constantinos (eds) On Pythagoreanism. Berlin/Boston: De Gruyter, 2013, p. 117-152.

. Pitagóricos en la comedia griega. In Fernández, Ángel Martínez et al. 
(eds) Ágalma. Ofrenda Desde la Filología Clásica a Manuel García Teijeiro. Valladolid: Ediciones Universidad de Valladolid, 2014, p. 477-483.

Transfer of afterlife knowledge in Pythagorean eschatology. In Renger, Almut-Barbara y Stravru, Alessandro (eds) Pythagorean Knowledge From the Ancient to the Modern World: Askesis, Religion, Science. Wiesbaden: Harrasowicz, 2016, p. 17-30.

. Two Orphic images in Euripides: Hippolytus 952-957 and Cretans 472 Kannicht. In Assaël, Jacqueline y Markantonatos, Andreas (eds) Orphism and Greek Tragedy (Trends in Classics 8). Berlin: DeGruyter, 2016a, p. 183-204.

Bernabé, Alberto y Casadesús, Francesc (eds) Orfeo y la Tradición Órfica. Un Reencuentro. Madrid: Akal, 2008.

Bernabé, Alberto; Kahle, Madayo; Santamaría, Marco Antonio (eds) Reencarnación. La Transmigración de las Almas Entre Oriente y Occidente. Madrid: Abada, 2011.

Bernabé, Alberto; Pérez de Tudela, Jorge (eds) Mitos Sobre el Origen del Hombre. Madrid: Círculo de Bellas Artes, 2011.

Blomqvist, Jerker. The Orphic fragment n. 292 Kern. In Teodorsson, Sven-Tage (ed.) Greek and Latin Studies in Memory of Cajus Fabricius. Göteborg: Acta Universitatis Gotoburgensis, 1990, p. 81-89.

Burkert, Walter. Homo Necans. The Anthropology of Ancient Greek Sacrificial Ritual and Myth. Berlin/New York: University of California Press, 1983.

. Religión Griega Arcaica y Clásica, Madrid: Abada, 2007.

Casadio, Giovanni. I Cretesi di Euripide e l'ascesi orfica. Didattica del Classico 2, Foggia 1990, p. 278-310.

La metempsicosi tra Orfeo e Pitagora. In Borgeaud, Philippe (ed.) Orphisme et Orphée, en l'Honneur de Jean Rudhardt. Genève: Droz, 1991, p. 119155 .

Cavanaugh, Maureen B. Eleusis and Athens. Documents in Finance, Religion and Politics in the Fifth Century. Atlanta, GA: American Philological Association, 1996.

De Paz Amérigo, Pablo; Flores Rivas, María. La transmigración en animales en el orfismo, ¿influencia pitagórica?. In: Nunc Est Bacchandum. Homenaje a Alberto Bernabé. Madrid: Guillermo Escolar (en prensa).

Detienne, Marcel. Les chemins de la déviance: Orphisme, dionysisme et pythagorisme. In Orfismo in Magna Grecia. Napoli: Arte Tipografica, 1975, p. 49-79.

Detienne, Marcel; Vernant, Jean Pierre (eds) La Cuisine du Sacrifice en Pays Grec. Paris: Gallimard, 1979.

Edmonds, Radcliffe. Tearing apart the Zagrus myth: A few disparaging remarks on Orphism and Original Sin. Classical Antiquity, 18, 1999, p. 35-73.

Herrero de Jáuregui, Miguel. El orfismo, el génos y la pólis. In Bernabé, Alberto y Casadesús, Francesc (eds) Orfeo y la Tradición Órfica. Un Reencuentro. Madrid: Akal, 2008, p. 1603-1624. 
Jiménez San Cristóbal, Ana Isabel. Rituales Órficos. Tesis Doctoral de la Universidad Complutense de Madrid. Madrid, 2002, accesible online.

El ritual y los ritos órficos. In Bernabé, Alberto y Casadesús, Francesc (eds) Orfeo y la Tradición Órfica. Un Reencuentro. Madrid: Akal, 2008, p. 731770.

Matheson, Susan B. The mission of Triptolemus and the politics of Athens. Greek, Roman and Byzantine Studies, 35, 1994, p. 345-372.

Newmyer, Stephen T. Animals, Rights and Reason in Plutarch and Modern Ethics, London: Routledge, 2013.

Pinnoy, Mauritis. Plutarque et l'Orphisme. Ancient Society, 21, 1990, p. 201-214.

Riedweg, Christoph. Pythagoras. His Life, Teaching and Influence, Ithaca/London: Cornell University Press, 2008.

Rudhardt, Jean. Notions Fondamentales de la Pensée Religieuse et Actes Constitutifs du Culte dans la Grèce Classique. $1^{\text {a }}$ Ed. 1958. Paris: Picard, 1992.

Schwarz, Gerda. Triptolemos. Ikonographie einer Agrar- und Mysteriengottheit, Graz: F. Berger, 1987.

. Triptolemos. In Lexicon Iconographicum Mythologiae Classicae. Zürich: Artemis, VIII, 1, 1997, p. 56-68.

Schuddeboom, Feyo L. Greek Religious Terminology - Telete \& Orgia. A Revised and Expanded English Edition of the Studies by Zijderveld and Van der Burg. Leiden/Boston: Brill, 2009.

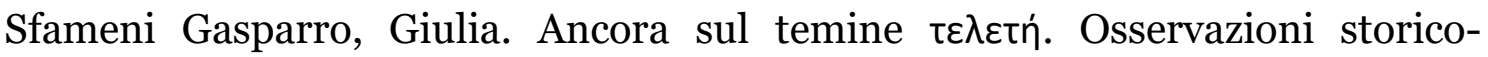
religiose. In: Studi Offerti a Francesco della Corte 5. Urbino: Università degli Studi di Urbino, 1988, p. 137-152.

Zatta, Claudia. Interconnectedness. The Living World of the Early Greek Philosophers. Sankt Augustin: Academia Verlag, 2017. 